\title{
Development of Candidate Teachers' Problem Solving Ability With the Audience Response System
}

\author{
Cüneyt Taşkın ${ }^{1} \&$ Tolga Kaan Bahadır ${ }^{2}$ \\ ${ }^{1}$ Kırkpınar Faculty of Sport Sciences, Trakya University, Turkey \\ ${ }^{2}$ Faculty of Sport Sciences, Kocaeli University, Turkey \\ Correspondence: Cüneyt Taşkın, Kırkpınar Faculty of Sport Sciences, Trakya University, Balkan Campus, \\ Edirne, Turkey. E-mail: cuneyttaskin@trakya.edu.tr
}

Received: January 12, 2021 Accepted: February 17, 2021 Online Published: February 20, 2021

doi:10.5539/jel.v10n2p91 URL: https://doi.org/10.5539/jel.v10n2p91

\begin{abstract}
In this study, the Audience Response System was investigated as an additional tool for interaction, and its effects on the educational environment were examined. The system was implemented at the Faculty of Sports Sciences of Trakya University in the fall semester of the 2019-2020 academic year. A pre-test of 20 questions, which was asked in the educational sciences section of the public personnel selection examination and had a similar item difficulty index, was applied to the experimental and control groups prior to the implementation of the ARS. Then, the experimental group was asked to solve the educational sciences questions with the help of the ARS-supported lectures, which were delivered $4 \mathrm{~h}$ a week for a total of $16 \mathrm{~h}$. The same implementation was imposed on the control group without the ARS support and with the classical recitation method. A post-test of 20 questions with a similar item difficulty index was administered to both groups after this test. Data were analyzed using the SPSS 25.0 package program. A t-test was used to determine the differences between the arithmetic mean of the pre-test and post-test scores of the students. Because the unequaled control group method was used in the experiment design, the "ANOVA for Repeated Measurements" was used for intragroup and intergroup comparisons. In conclusion, it was determined that the implementation of interactive interaction technologies in the educational environment will capture the interest of students and amplify their motivation levels. The results of the study support the conclusion that the ARS system stimulates the sensory organs in terms of understanding the subject, thereby increasing the level of learning.
\end{abstract}

Keywords: audience response system, teacher candidates, physical education, experimental study

\section{Introduction}

Creation of the optimal learning environment for educational practices has been attempted by using various methods and techniques. It is known that quality interaction occurring in the classroom helps students identify with the lesson and makes them more active and willing. Multiple choice questions, which are the products of the examination system that students face in all stages of their education life, are important skills that require practice. Augmented attention and motivation levels are expected from students who are constantly interacting and answering questions in the classroom; thereby resulting in an increase in problem-solving skills. In this regard, using ever-developing technology is crucial for all educators.

The formation of healthy in-class communication is based on teacher, student, and environmental factors (Selimhocaoğlu, 2004). It is possible to see three types of communication: verbal, non-verbal, and technological tool assistance in these environments. Educators use various methods, techniques, and tools to create and maintain an effective communication environment. One of the solutions provided to increase the in-class interaction and to show the answers to the questions asked by students is using the Audience Response System (ARS, Trapskin et al., 2005). The ARS has different names, such as the Audience Response System (ARS), Personal Response System (PRS), and Clicker, in the literature. In addition to being used at all stages of education (Caldwell, 2007), these systems are used to obtain audience responses in many game shows. The ARS eases the process by asking questions about the information provided or to be provided to students and obtaining answers, assessing the responses with or without user tracking, and carrying out discussions about these. The ARS can be defined as a combination of electronic devices and software that enable obtaining statistical information about the responses and presenting them to students. The studies in the literature revealed that the 
use of the ARS in learning environments impacts student engagement, course satisfaction, and academic achievement. Accordingly, it was revealed that the ARS caused a 20-30\% increase in spots like sharing time and total acquired knowledge, increased the student engagement at the rate of $27 \%$ whereas conventional methods displayed only a $19 \%$ increase, and it increased permanence more compared to students who took the same course with conventional methods, and was greatly appreciated (Horawitz, 2007). The ARS also contributes to time management and formative evaluation matters (Beatty et al., 2006).

The literature establishes that teachers mainly approve of this system and find it useful and interesting. Guthrine and Carlin (2007) stated that $28 \%$ of the participants believed the use of the ARS to be efficient despite its cost. In addition, educators stated that this system made the class more happy, friendly, and active. Moreover, the majority of the participants stated that they wanted to use ASR in their works (Abrahamson, 2006). In studies where the opinions of students and teachers were examined, both teachers and students approached the system positively and believed that the ARS raised their interest and participation. Kift (2006) reported that $90 \%$ of the students understood the subjects better, exhibited greater lesson participation, and had more fun thanks to the ARS. In addition, students expressed that the ARS encouraged them to respond (Latessa \& Mouw, 2007). The majority of the students stated that they did not encounter any problems regarding the sender (Preszler et al., 2007). In short, the ARS aids teachers in retaining the active interest of students while observing the understanding level of the whole class and providing suitable feedback (Martyn, 2007). In this regard, it is possible to state that the ARS is a tool that builds a socially centered learning environment, makes teachers sensitive towards requisite changes, and establishes a learning communication (Banks, 2006). It is necessary to have the proper pedagogical structure for the ARS to serve in the best way possible. Thus, sharing the implementations and results of the system in scientific areas ensures the formation of this structure. However, the number of studies on the use of response systems is quite low in Turkey. This study focused on the use and evaluation of the ARS.

The ARS is a technology that aims to increase communication possibilities through hardware and software. In other words, the ARS enables teachers and students to present information in the educational environment, conduct discussions about the information, pose questions about the information provided or to be provided and get answers to these questions, and evaluate these answers with or without user tracking. In addition, the ARS can be defined as a combination of electronic devices and software that facilitates the acquisition of statistical information about the responses when desired and presents them to students. A prominent feature of the ARS is that it is an in-class response system.

\subsection{Components of the Audience Response System}

Kift (2006) defined the ARS as devices allowing synchronized communication between the teacher and student independent of the size of the class and the number of students. According to another definition, the ARS is the collection of software and hardware that enables the audience to answer or respond to situations created by the operator. Students can provide immediate responses and feedback during class via their keypads.

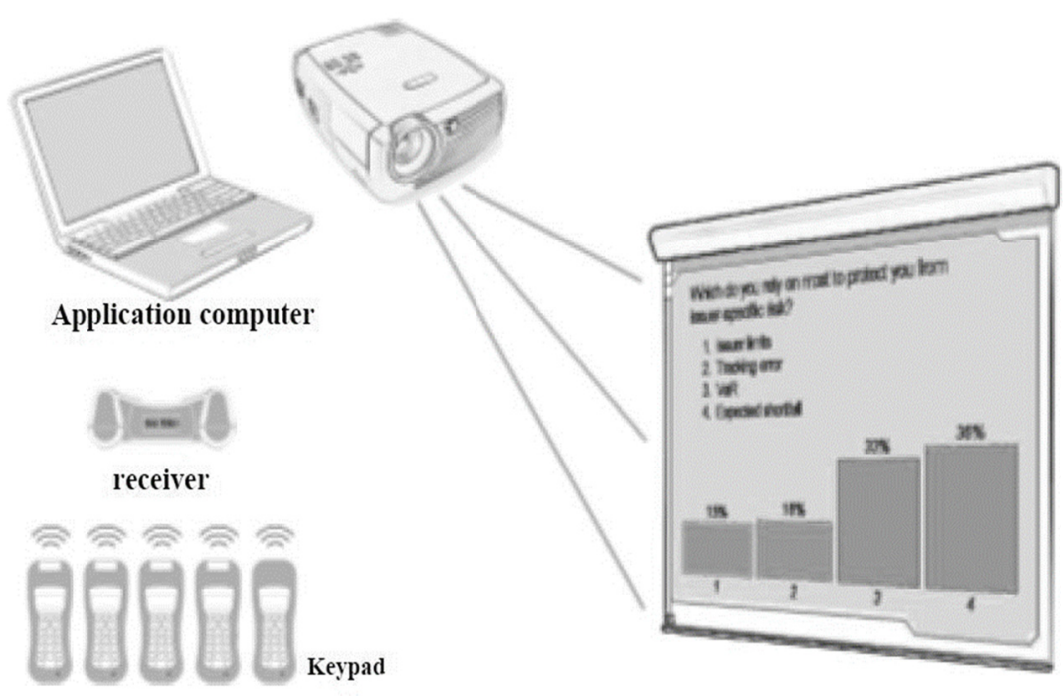

Figure 1. Components of the audience response system 
There is no consensus on defining and naming the in-class response systems. McCabe (2006) listed the commonly used response systems as follows:

- Electronic Voting System

- Group Decision Support Systems

- Personal Response System

- Audience Response System

- Group Response System

- Classroom Communication System

\subsection{Problem Status}

What are the effects of the audience response system on physical education and the ability of sports teachers to solve multiple-choice problems?

\section{Method}

This study used the quasi-experimental research method (Cohen, Manion, \& Morrison, 2000). As required by the method, the experimental and control groups were not randomly assigned and the equality of the groups was considered. The only difference between this method and the actual experimental method is that the sample is not formed randomly. Measurements were conducted before and after the experiment in both groups. The pre-test and post-test measurement results were used in conjunction to determine the efficacy of the teaching method used in this study.

\subsection{Participant and Sampling Procedures}

The population of the study included 227 students studying in the Department of Physical Education Teaching in the Kırkpınar School of Physical Education and Sports at Trakya University. Ethical committee permission was obtained before sample selection. A total of 80 students (10 men and 10 women from each class) with the highest general academic average were selected for the sample group of the multi-repetitive experimental study. Of these students, two groups (experiment and control) of 20 men and 20 women were formed using the random sampling method.

\subsection{Implementation}

The model was implemented at the Faculty of Sports Sciences of Trakya University in the fall semester of the 2019-2020 academic year. A pre-test of 20 questions that were asked in the educational sciences section of the public personnel selection examination (KPSS) and had a similar item difficulty index was applied to the experimental and control groups prior to the implementation. Then, the experimental group was asked to solve the educational sciences questions with the ARS-supported lectures $4 \mathrm{~h}$ a week for a total of $16 \mathrm{~h}$. The same model was implemented for the control group without the ARS support and with the classical recitation method. After the end of the implementation, a post-test of 20 questions with a similar item difficulty index was administered to both groups. In the continuation of these measurements, the groups were intercrossed and the measurement methodology was repeated, and the second implementation was made. The reason why the groups were intercrossed and the measurements were repeated is to eliminate the placebo effect as in the examinations of drug effectiveness in medical sciences. The correlation between the experimental and control groups that were exposed to the same processes is considered to properly explain the effect of the ARS system. The methodology model of this study is given below. 


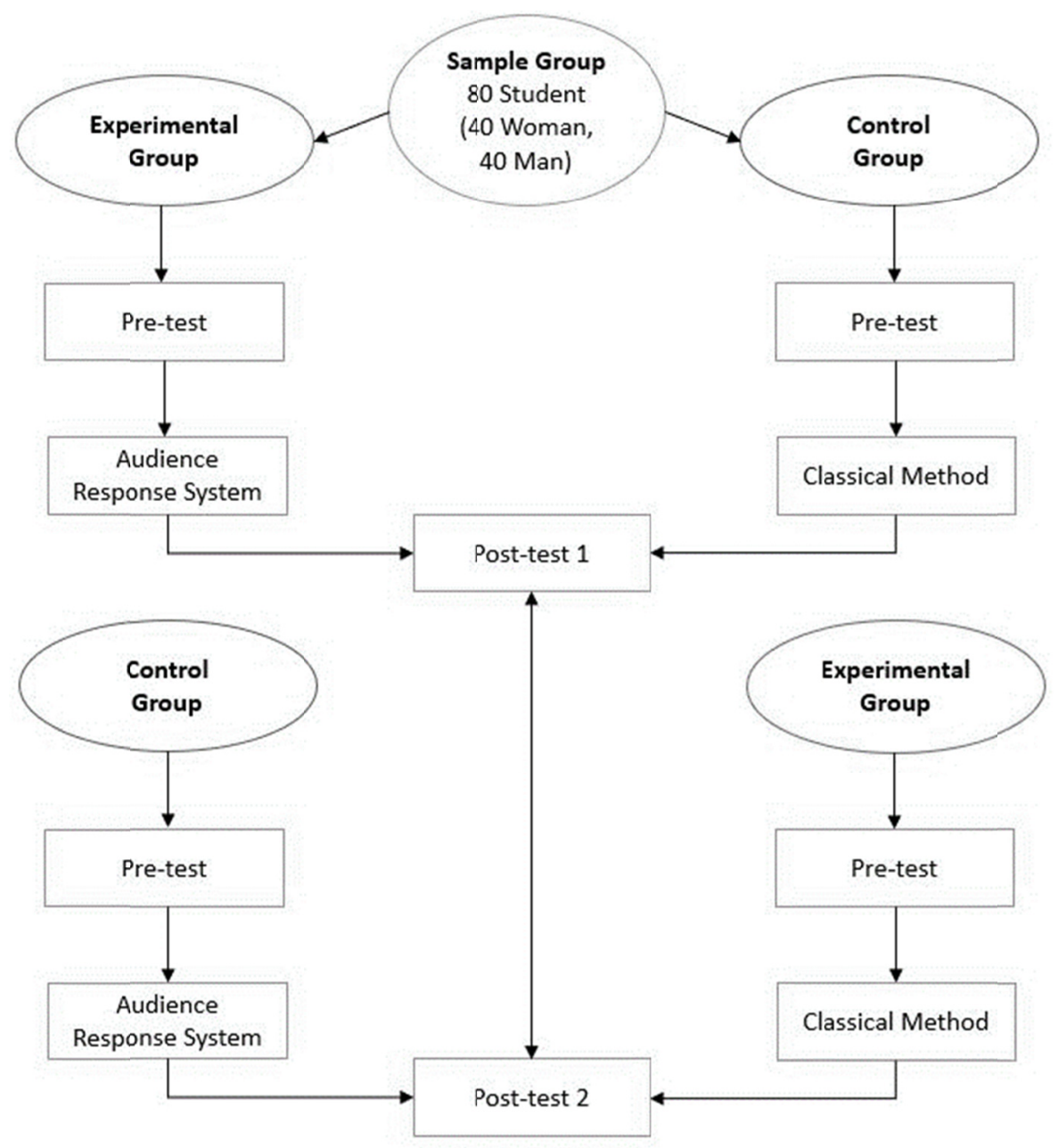

Figure 2. Graph of the methodology model

\subsection{Analysis}

Data were analyzed using the SPSS 25.0 package program. Accordingly, kurtosis and skewness measurements and Shapiro-Wilk values were used to determine whether the study data were distributed normally. According to the results, the values between -1 and +1 indicated a normal distribution, whereas other values indicated a non-normal distribution. In addition, the distribution with a Shapiro-Wilk significance level higher than 0.05 was normal and lower than 0.05 was not normal (Tabachnick \& Fidell, 2013; George \& Mallery, 2010). For both measurements conducted (for the situation wherein the ARS was used and the classical method), skewness kurtosis values of the data were between -1 and +1 (ARS: $-0.205-0.634$ Classical: -.145 -.922), and this showed that the distribution was normal. Further, Kolmogorov-Smirnov and Shapiro-Wilk values were higher than 0.05 ; thus, revealing that data were distributed normally in this study. A t-test was used to determine the differences between the arithmetic mean for the pre-test and post-test scores of the students. Since the unequaled control group method was used in the experiment design, the "ANOVA for Repeated Measurements" was used for intragroup and intergroup comparisons.

\section{Results}

In this experimental study, which examined the effect of using the ARS in recitation on the ability to solve multiple-choice questions, multiple-choice question tests were administered before and after the lectures to a group of 40 students who were given educational science lectures using the ARS system and another group of 40 students who were given educational science lectures using the classical method. The test results are as follows: 
Table 1. First measurement independent groups t-test results

\begin{tabular}{llllllll}
\hline Method & N & $\overline{\boldsymbol{x}}$ & Sd. & Sd. & $\mathbf{t}$ & $\mathbf{p}$ & Effect size \\
\hline Classical & 40 & 11.51 & 2.093 & 78 & 3.700 & $.00^{*}$ & 0.8273 \\
ARS & 40 & 13.09 & 1.697 & & & & \\
\hline
\end{tabular}

Note. $* \mathrm{p}<\frac{A R S}{<.05 \text {. }}$

According to the test results of the first measurement, there was a significant difference between the ARS system and the classical problem-solving method. $[\mathrm{t}(78)=3.700, \mathrm{p}<0.05]$ The effect size was calculated using Cohen's $\mathrm{d}$ formula and found to be 0.8273 . This value demonstrates that using the ARS significantly affected the ability of candidates and teachers to solve multiple-choice problems.

Table 2. Second measurement independent groups t-test results

\begin{tabular}{llllllll}
\hline Method & N & $\overline{\boldsymbol{x}}$ & Sd. & Sd. & t & p & Effect size \\
\hline Classical & 40 & 11.92 & 2.364 & 78 & 4.036 & $.00^{*}$ & 0.902
\end{tabular}

Note. $* \mathrm{p}<\frac{A R S}{<.05 .}$

According to the test results of the second measurement, there was a significant difference between the ARS method and the classical method. [t(78) $=3.700, \mathrm{p}<0.05]$ The effect size was calculated using Cohen's $\mathrm{d}$ formula and was found to be 0.902 . This value demonstrates that using an ARS significantly affects the ability of candidates and teachers to solve multiple-choice problems.

Table 3. Repeated measurement test results

\begin{tabular}{lllllll}
\hline \multirow{2}{*}{ Groups } & \multicolumn{7}{c}{ Post-test 1 } & \multicolumn{5}{c}{ Post-test 2 } \\
\cline { 2 - 7 } & $N$ & $\bar{x}$ & $S$ & $N$ & $\bar{x}$ & $S$ \\
\hline Experimental group & 40 & 11.52 & 2.09 & 40 & 14.61 & 1.94 \\
Control group & 40 & 11.44 & 2.32 & 40 & 13.48 & 2.45 \\
\hline
\end{tabular}

The two-factor variance analysis for the mixed measurements examined whether being in the group where the ARS was used had a significant effect on the post-test scores. The group-measurement common effect showed that the increase in the scores of the ARS group was significantly higher than that of the other group $\left[\mathrm{F}_{(1-78)}=5.6\right.$, $\mathrm{p}<0.05]$. Thus, it can be concluded that using the ARS in educational science courses has a significant effect on the success of solving multiple-choice questions. The graphical demonstration drawn to predict this effect is given below.

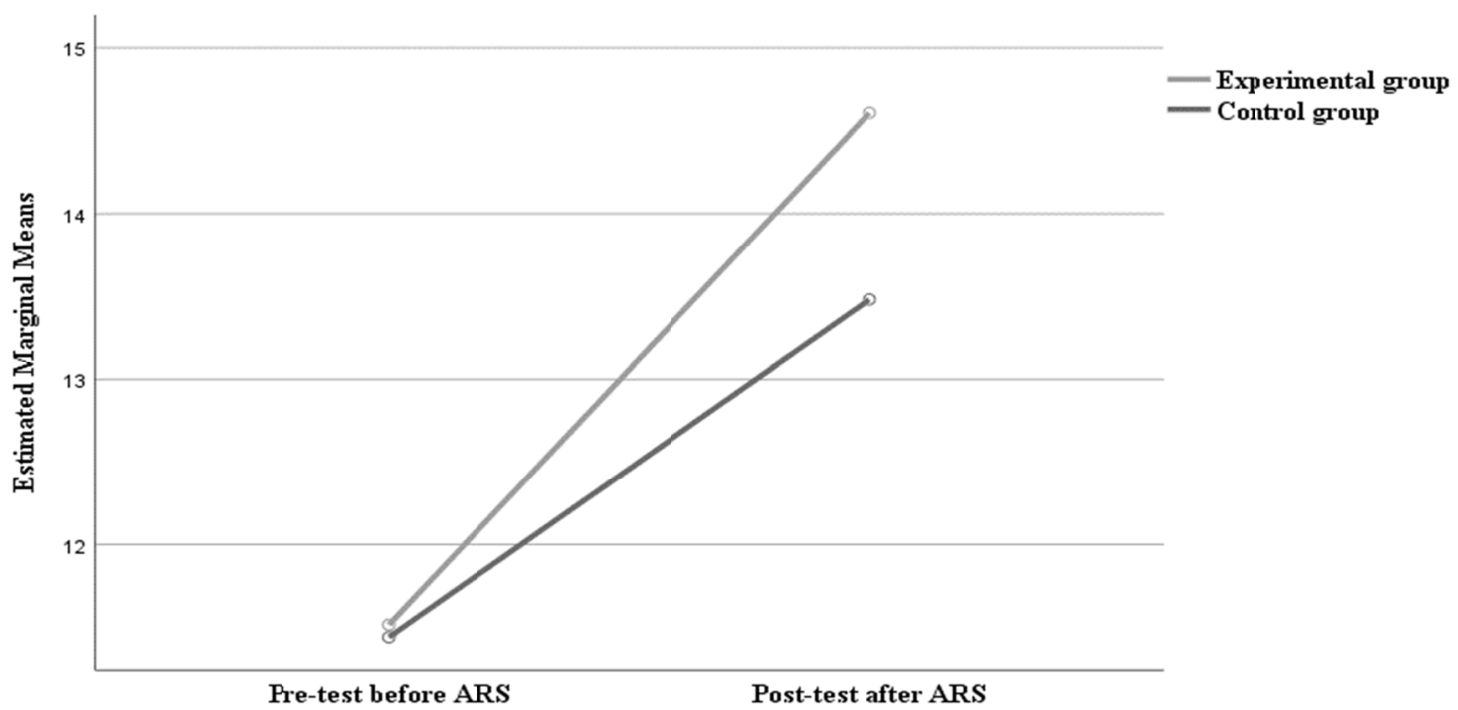

Figure 3. Development graph of the groups before and after the ARS 
As seen in the graph, the group means that were close in the first measurement changed in favor of the experimental group in the second measurement. It was found that the use of the ARS significantly affected the group means of both groups.

\section{Discussion}

The aim of this study was to examine the use of the ARS, an additional tool for interaction, and its effects on the educational environment. The opinions of the students were obtained at the end of the 8-week-long implementation of this system. According to the analysis results, verbal feedback indicated that the ARS positively affected in-class education in terms of providing active participation, increasing motivation, and focus. The positive effects of the ARS can be explained by the fact that it acts as an effective communication channel between the student-teacher and the teacher-student. The obligation of each student to respond is an incentive for them to stay active (McCabe, 2006). The continuance of motivation, participation, and interaction might have made the students think that they learned more (Johnson, 2005). However, it should not be disregarded that the method related issues such as the quality of the feedback given, the discussion of the answers by showing the statistics to the class, the type, number, and frequency of the questions asked are as important as the system itself. In other words, positive opinions should be evaluated not only with the hardware and software of the system, but also with the question-answer method conducted. Thus, the implementation of the ARS in question-answer and classroom discussion activities was received positively by the students.

The fact that feedback is administered instantly is expected to boost success and interest (Dominick \& Bishop, 2006; Pennuel et al., 2005). Students were able to receive feedback about their responses more rapidly thanks to the ARS. It effectively provided students with the chance to observe their situations and gave them the opportunity to make the required modifications in their learning. This effect can be explained by the fact that the ARS allows in-class information sharing and supplies the opportunity to see different opinions and reasons (Hinde \& Hunt, 2006). This participation made the learners happy and generated a cheerful classroom atmosphere (Horawitz, 2007; Guthrine \& Carlin, 2007). The easy use of the ARS and its ability to provide rapid integration and effect is an important factor for the students to embrace the system and view its use in other courses in a positive manner.

The number of relevant studies in the literature is quite low. The ARS was used in recitation, and its contribution to the lecture was examined in relevant studies. Yildırım S. S. et al. (2014) conducted a study on police school students with the ARS and found no difference between the students in the experimental and control groups. It was implemented in the recitation in that study and was not used in relation to problem-solving ability, as in the present study. According to the results obtained, the ARS has an effect on problem-solving ability. This result generates various generalizations.

Even though the accuracy in the sampling and multi-repetitive measurements minimized the difference between the groups, the generalizability of qualitative studies conducted with human subjects is inquired. Humans respond differently to many stimuli due to their nature, meaning that they can also respond differently to the same stimulus. The diversity of the stimuli, such as the status of the physical environment, psychological state, measurement method, the person taking the measurement, and the variable measured affects this differentiation. The averages of the three different measurements evaluated in this study were determined for a healthy and reliable measurement in order to ensure the consistency of an average human response.

There was a statistically significant difference between the ARS group and the classical method group in the first measurement, and it was found that the ARS method positively contributed to problem solving. According to the results of the second measurement obtained after changing the groups, a significant difference was found between the group that transferred from the classical method to the ARS and the other group. There was an increase in the means of problems solved in both groups as the system was used. The last measurement was considered the post-test of the first measurement, and the last tests of the second measurement were considered the repeated tests, and the time graph for the development of the system was drawn. As depicted in the graph, the ability to solve multiple-choice problems in the educational sciences field improved in both groups as a result of using the ARS.

\section{Conclusion}

In conclusion, it has been determined that the use of interactive interaction technologies in an educational environment will capture the interest of students and motivate them. The results of the study support the conclusion that the ARS system stimulates the sensory organs in terms of understanding the subject, thereby increasing the level of learning. Another advantage of the use of this technology is that the students interacted with their friends during the problem-solving process, exchanged questions with each other, and finally marked 
the answer option with their own ideas. This situation helped students socialize and supported cooperative learning. Scientists and students who conduct academic studies are obligated to conduct studies on the use of the ARS and similar technologies in educational activities to keep pace with the rapidly changing and developing education system.

\section{References}

Abrahamson, L. (2006). A brief history of networked classrooms: Effects, cases, pedagogy, and implications. In D. A. Banks (Ed.), Audience response system in higher education: Applications and cases (pp. 1-25). Hershey, PA: Information Science. https://doi.org/10.4018/978-1-59140-947-2.ch001

Banks, D. A. (2006). Reflection on the use of ARS with small groups. In D. A. Banks (Ed.), Audience response system in higher education: Applications and cases (pp. 373-386). Hershey, PA: Information Science. https://doi.org/10.4018/978-1-59140-947-2.ch025

Beatty, I. D., Leonard, W. J., Grace, W. J., \& Dufresne, R. J. (2006). Question driven instruction: Teaching science (well) with an audience response system. In D. A. Banks (Ed.), Audience response system in higher education: Applications and cases (pp. 96-115). Hershey, PA: Information Science. https://doi.org/10.4018/978-1-59140-947-2.ch007

Caldwell, J. E. (2007). Clickers in the large classroom: Current research and best-practice tips. CBE-Life Sciences Education, 6(1), 9-20. https://doi.org/10.1187/cbe.06-12-0205

Cohen, L., Manion, L., \& Morrison, K. (2000). Research methods in education (5th ed.). London: Routledge.

Dominick, J., \& Bishop, A. (2006). Instructor mobile audience response system. In D. A. Banks (Ed.), Audience response system in higher education: Applications and cases (pp. 347-358). Hershey, PA: Information Science. https://doi.org/10.4018/978-1-59140-947-2.ch023

Fidell, S., Tabachnick, B., Mestre, V., \& Fidell, L. (2013). Aircraft noise-induced awakenings are more reasonably predicted from relative than from absolute sound exposure levels. The Journal of the Acoustical Society of America, 134(5), 3645-3653. https://doi.org/10.1121/1.4823838

George, D., \& Mallery, P. (2010). SPSS for Windows step by step. A simple study guide and reference (10. Bask1). GEN, Boston, MA: Pearson Education, Inc.

Guthrie, R. W., \& Carlin, A. (2007). Waking the dead: Using interactive technology to engage Passive listeners in the classroom. Retrieved July 30, 2011, from $\mathrm{http} / /$ www.audienceresponseinfo.com/interactive-technology-classroom/

Hinde, K., \& Hunt, A. (2006). Using the personal response system to enhance student learning: Some evidence from teaching economics. In D. A. Banks (Ed.), Audience response system in higher education: Applications and cases (pp. 140-154). Hershey, PA: Information Science. https://doi.org/10.4018/978-1-59140-947-2.ch010

Horawitz, H. M. (2006). ARS Evolution: Reflection and Recommendations (Chapter 4). Audience Response System in Higher Education: Application and Cases. https://doi.org/10.4018/978-1-59140-947-2.ch004

Horowitz, H. M. (2007). Adding more power to PowerPoint using audience response technology. Retrieved from $\mathrm{http} / / / \mathrm{www}$.audienceresponseinfo.com/adding-more-power-to-powerpointusing-audience-response-technolo gy/

Johnson, J. T. (2005). Creating learner-centered classroms: Use of an audience response system in pediatric dentistry education. Journal of Dental Education, 69(3), 378-381. https://doi.org/10.1002/j.0022-0337.2005.69.3.tb03925.x

Kift, S. (2006). Using audience response system to enhance student engagement in large group orientation: A law faculty case stuARS. In D. A. Banks (Ed.), Audience response system in higher education: Applications and cases (pp. 80-95). Hershey, PA: Information Science. https://doi.org/10.4018/978-1-59140-947-2.ch006

Latessa, R., \& Mouw, D. (2007). Use of an audience response system to augment interactive learning: Audience response systems for medical teaching.

Martyn, M. (2007). Clickers in the classroom: An active learning approach. EDUCAUSE Quarterly, 30(2), $71-74$.

McCabe, M. (2006). Live assessment by questioning in an interactive classroom. In D. A. Banks (Ed.), Audience 
response system in higher education: Applications and cases (pp. 276-288). Hershey, PA: Information Science. https://doi.org/10.4018/978-1-59140-947-2.ch018

Penuel, W. R., Crawford, V., DeBarger, H., Boscardin, C. K., Masyn, K., \&Urdan, T. (2005). Teaching with student response system technology: A survey of K-12 Teachers. Retrieved July 10, 2011, from http://ctl.sri.com/publications/downloads/Teaching_with_Audience_Response_Systems_Brief_Report.pdf.

Preszler, R. W., Dawe, A., Shuster, C. B., \& Shuster, M. (2007). Assessment of the effects of student response systems on student learning and attitudes over a broad range of biology courses. CBE-Life Sciences Education, 6, 29-41. https://doi.org/10.1187/cbe.06-09-0190

Selimhocaoğlu, A. (2004). İletişim ve sınıf içi iletişsimin önemi. XIII. Ulusal Eğitim Bilimleri Kurultayı'nda sunulan bildiri. İnönü Üniversitesi, Eğitim Fakültesi, Malatya, Türkiye, 6-9 Temmuz.

Trapskin, P. J., Smith, K. M., Armitstead, J. A., \& Davis, G. A. (2005). Use of an Audience Response System to Introduce an Anticoagulation Guide to Physician, Pharmacist and Pharmacy Students. American Journal of Pharmaceutical Education, 69(2), article 28. https://doi.org/10.5688/aj690228

Yıldırım, S., Karaman, S., \& Zengin, S. (2014). Dinleyici Yanıt Sisteminin Öğrenci Gelişimine Etkileri: Erzurum Polis Okulu Örneği, K. Ü. Kastamonu Eğitim Dergisi, 23(2), 467-478.

\section{Copyrights}

Copyright for this article is retained by the author, with first publication rights granted to the journal.

This is an open-access article distributed under the terms and conditions of the Creative Commons Attribution license (http://creativecommons.org/licenses/by/4.0/). 